Published on Web 01/12/2008

\title{
Lanthanide-Binding Peptides for NMR Measurements of Residual Dipolar Couplings and Paramagnetic Effects from Multiple Angles
}

\author{
Xun-Cheng Su, ${ }^{\dagger}$ Kerry McAndrew, ${ }^{\ddagger}$ Thomas Huber,, and $^{-}$Gottfried Otting ${ }^{*}, \dagger$ \\ Research School of Chemistry and John Curtin School of Medical Research, Australian National \\ University, Canberra ACT 0200, Australia, and School of Molecular and Microbial Sciences and \\ Australian Institute for Bioengineering and Nanotechnology, University of Queensland, \\ Brisbane QLD 4072, Australia
}

Received August 31, 2007; E-mail: gottfried.otting@anu.edu.au

\begin{abstract}
Lanthanide-binding peptide tags (LBTs) containing a single cysteine residue can be attached to proteins via a disulfide bond, presenting a flexible means of tagging proteins site-specifically with a lanthanide ion. Here we show that cysteine residues placed in different positions of the LBT can be used to expose the protein to different orientations of the magnetic susceptibility anisotropy $(\Delta \chi)$ tensor and to generate different molecular alignments in a magnetic field. $\Delta \chi$ tensors determined by nuclear magnetic resonance (NMR) spectroscopy for LBT complexes with $\mathrm{Yb}^{3+}, \mathrm{Tm}^{3+}$, and $\mathrm{Er}^{3+}$ suggest a rational way of producing alignment tensors with different orientations. In addition, knowledge of the $\Delta \chi$ tensor of LBT allows modeling of the protein-LBT structures. Despite evidence for residual mobility of the LBTs with respect to the protein, the pseudocontact shifts and residual dipolar couplings displayed by proteins disulfide-bonded to LBTs are greater than those achievable with most other lanthanide binding tags.
\end{abstract}

\section{Introduction}

Site-specific attachment of lanthanide ions to proteins provides a rich source of paramagnetic effects which offer unique opportunities for NMR studies of the structure and dynamics of proteins and protein-ligand complexes in solution. ${ }^{1-8}$ The attraction of lanthanide ions lies in their chemical similarity but greatly varying paramagnetic properties. In particular, the ionic radii of the diamagnetic ions $\mathrm{La}^{3+}, \mathrm{Lu}^{3+}$, and $\mathrm{Y}^{3+}$ are very similar to those of the paramagnetic lanthanides so that a diamagnetic reference state of nearly identical structure can easily be obtained. Lanthanides with anisotropic magnetic susceptibility anisotropy tensor $\Delta \chi$ offer particularly valuable structural information presented by pseudocontact shifts (PCS) and residual dipolar couplings (RDCs) arising from magnetic-field induced partial alignment of the lanthanide-labeled molecules. ${ }^{9}$

PCS are described by

Research School of Chemistry, Australian National University.

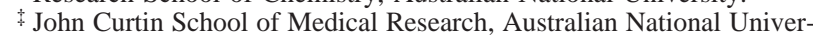
sity.

$\S$ University of Queensland.

(1) Allegrozzi, M.; Bertini, I.; Janik, M. B. L.; Lee, Y. M.; Liu, G. H.; Luchinat, C. J. Am. Chem. Soc. 2000, 122, 4154-4161.

(2) Bertini, I.; Del Bianco, C.; Gelis, I.; Katsaros, N.; Luchinat, C.; Parigi, G.; Peana, M.; Provenzani, A.; Zoroddu, A. M. Proc. Natl. Acad. Sci. U.S.A. 2004, 101, 6841-6846.

(3) Gaponenko, V.; Sarma, S. P.; Altieri, A. S.; Horita, D. A.; Li, J.; Byrd, R. A. J. Biomol. NMR 2004, 28, 205-212.

(4) Pintacuda, G.; Keniry, M. A.; Huber, T.; Park, A. Y.; Dixon, N. E.; Otting, G. J. Am. Chem. Soc. 2004, 126, 2963-2970.

(5) Rodriguez-Castañeda, F.; Haberz, P.; Leonov, A.; Griesinger, C. Magn. Reson. Chem. 2006, 44, S10-S16.

(6) John, M.; Pintacuda, G.; Park, A. Y.; Dixon, N. E.; Otting, G. J. Am. Chem. Soc. 2006, 128, 12910-12916.

(7) Pintacuda, G.; John, M.; Su, X.-C.; Otting, G. Acc. Chem. Res. 2007, 40, $206-212$.

(8) Eichmüller, C.; Skrynnikov, N. R. J. Biomol. NMR 2007, 37, 79-95.

10.1021/ja076564I CCC: $\$ 40.75$ @ 2008 American Chemical Society

$$
\begin{aligned}
& \Delta \delta^{P C S}= \\
& \quad \frac{1}{12 \pi r^{3}}\left[\Delta \chi_{a x}\left(3 \cos ^{2} \theta-1\right)+1.5 \Delta \chi_{r h} \sin ^{2} \theta \cos 2 \phi\right]
\end{aligned}
$$

where $r, \theta$, and $\phi$ are the polar coordinates of the nuclear spin with respect to the principal axes of the $\Delta \chi$ tensor, and $\Delta \chi_{\text {ax }}$ and $\Delta \chi_{\mathrm{rh}}$ are the axial and rhombic components of the $\Delta \chi$ tensor, respectively. ${ }^{9}$ The RDC $D_{\mathrm{AB}}$ between spins A and B is described by a very similar equation

$$
\begin{aligned}
& D_{A B}= \\
& \quad-\frac{S \gamma_{A} \gamma_{B} \mu_{0} \hbar}{8 \pi^{2} r_{A B}^{3}}\left[A_{a x}\left(3 \cos ^{2} \partial-1\right)+1.5 A_{r h} \sin ^{2} \partial \cos 2 \varphi\right]
\end{aligned}
$$

where $\partial$ and $\varphi$ describe the orientation of the internuclear vector in the principal axes system of the alignment tensor, $A_{\mathrm{ax}}$ and $A_{\mathrm{rh}}$ are the axial and rhombic components of the alignment tensor, $S$ is the generalized order parameter, $r_{\mathrm{AB}}$ is the internuclear distance, $\hbar$ is Planck's constant divided by $2 \pi, \mu_{0}$ is the magnetic permeability of vacuum, and $\gamma_{\mathrm{A}}$ and $\gamma_{\mathrm{B}}$ are the magnetogyric ratios of spins $\mathrm{A}$ and $\mathrm{B}$. In the case of a rigid molecule that is partially aligned to the magnetic field by virtue of its paramagnetism, the alignment tensor is directly proportional to the $\Delta \chi$ tensor:

$$
A_{a x, r h}=\frac{B_{0}^{2}}{15 \mu_{0} k T} \Delta \chi_{a x, r h}
$$

(9) Bertini, I.; Luchinat, C.; Parigi, G. Prog. NMR Spectrosc. 2002, 40, 249273.

J. AM. CHEM. SOC. 2008, 130, 1681-1687 -

1681 
where $B_{0}$ is the magnetic field strength, $k$ the Boltzmann constant, and $T$ the temperature.

Equations 1 and 2 show that a single PCS or RDC value can be interpreted by several different sets of angles. The number of solutions can, however, be reduced by collecting data from multiple, differently orientated $\Delta \chi$ and alignment tensors. RDCs measured for multiple alignments have long been shown to provide powerful strategies for structure analysis ${ }^{10-15}$ and studies of protein mobility. ${ }^{16-20}$ PCS induced by different lanthanide ions provide similar advantages for the analysis of the structure and mobility of proteins. ${ }^{2,6,7,21}$ In addition, PCS from different lanthanide ions offer outstanding opportunities for fast NMR resonance assignments by comparison with the $3 \mathrm{D}$ structure of the protein. ${ }^{4,22,23}$

Most proteins do not bind lanthanides specifically. Furthermore, the $\Delta \chi$ tensors of different lanthanide ions at a conserved binding site tend to be oriented similarly. ${ }^{21,24,25}$ This problem can be circumvented by the use of different lanthanide binding tags with intrinsically different $\Delta \chi$ tensors $^{5,26}$ or by attaching the same lanthanide tag at different sites of the protein. ${ }^{3}$ In addition, these strategies yield different molecular alignments in a magnetic field ${ }^{5,26}$ which can be difficult to achieve with conventional alignment media, if the protein is incompatible with the media. ${ }^{27}$

Several different lanthanide binding tags have been explored, including synthetic chelating agents, $3,26,28-33$ protein fusions with lanthanide binding peptide motifs, ${ }^{34-36}$ and a lanthanide binding peptide tag (LBT) chemically attached via a disulfide bond. ${ }^{37}$

(10) Ramirez, B. E.; Bax, A. J. Am. Chem. Soc. 1998, 120, 9106-9107.

(11) Sass, J.; Cordier, F.; Hoffmann, A.; Rogowski, M.; Cousin, A.; Omichinski, J. G.; Löwen, H.; Grzesiek, S. J. Am. Chem. Soc. 1999, 121, 2047-2055.

(12) Hus, J. C.; Peti, W.; Griesinger, C.; Brüschweiler, R. J. Am. Chem. Soc. 2003, 125, 5596-5597.

(13) Bernado, P.; Bertoncini, C. W.; Griesinger, C.; Zweckstetter, M.; Blackledge, M. J. Am. Chem. Soc. 2005, 127, $17968-17969$.

(14) Bax, A.; Grishaev, A. Curr. Opin. Struct. Biol. 2005, 15, 563-570.

(15) Bouvignies, G.; Meier, S.; Grzesiek, S.; Blackledge, M. Angew. Chem., Int. Ed. 2006, 45, 8166-8169.

(16) Peti, W.; Meiler, J.; Brüschweiler, R.; Griesinger, C. J. Am. Chem. Soc. 2002, 124, 5822-5833.

(17) Meiler, J.; Peti, W.; Griesinger, C. J. Am. Chem. Soc. 2003, 125, 80728073.

(18) Ulmer, T. S.; Ramirez, B. E.; Delaglio, F.; Bax, A. J. Am. Chem. Soc. 2003, 125, 9179-9191.

(19) Bouvignies, G.; Bernado, P.; Meier, S.; Cho, K.; Grzesiek, S.; Brüschweiler, R.; Blackledge, M. Proc. Natl. Acad. Sci. U.S.A. 2005, 102, 13885-13890.

(20) Tolman, J. R.; Ruan, K. Chem. Rev. 2006, 106, 1720-1736.

(21) Pintacuda, G.; Park, A. Y.; Keniry, M. A.; Dixon, N. E.; Otting, G. J. Am. Chem. Soc. 2006, 128, 3696-3702.

(22) Schmitz, C.; John, M.; Park, A. Y.; Dixon, N. E.; Otting, G.; Pintacuda, G.; Huber, T. J. Biomol. NMR 2006, 35, 79-87.

(23) John, M.; Schmitz, C.; Park, A. Y.; Dixon, N. E.; Huber, T.; Otting, G. J. Am. Chem. Soc. 2007, 129, 13749-13757.

(24) Bertini, I.; Janik, M. B. L.; Lee, Y. M.; Luchinat, C.; Rosato, A. J. Am. Chem. Soc. 2001, 123, 4181-4188.

(25) John, M.; Park, A. Y.; Dixon, N. E.; Otting, G. J. Am. Chem. Soc. 2007 $129,462-463$.

(26) Ikegami, T.; Verdier, L.; Sakhaii, P.; Grimme, S.; Pescatore, B.; Saxena, K.; Fiebig, K. M.; Griesinger, C. J. Biomol. NMR 2004, 29, 339-349.

(27) Ruan, K.; Tolman, J. R. J. Am. Chem. Soc. 2005, 127, 15032-15033.

(28) Dvoretsky, A.; Gaponenko, V.; Rosevear, P. R. FEBS Lett. 2002, 528, 189 192.

(29) Prudêncio, M.; Rohovec, J; Peters, J. A.; Tocheva, E.; Boulanger, M. J. Murphy, M. E. P.; Hupkes, H. J.; Kosters, W.; Impagliazzo, A.; Ubbink, M. Chem.-Eur. J. 2004, 10, 3252-3260.

(30) Leonov, A.; Voigt, B.; Rodriguez-Castañeda, F.; Sakhaii, P.; Griesinger C. Chem.-Eur. J. 2005, 11, 3342-3348.

(31) Haberz, P.; Rodriguez-Castañeda, F.; Junker, J.; Becker, S.; Leonov, A.; Griesinger, C. Org. Lett. 2006, 8, 1275-1278.

(32) Vlasie, M. D.; Comuzzi, C.; van den Nieuwendijk, A. M. C. H.; Prudêncio M.; Overhand, M.; Ubbink, M. Chem.-Eur. J. 2007, 13, 1715-1723.

(33) Keizers, P. H. J.; Desreux, J. F.; Overhand, M.; Ubbink, M. J. Am. Chem. Soc. 2007, 129, 9292-9293.

(34) Ma, C.; Opella, S. J. J. Magn. Reson. 2000, 146, 381-384

(35) Wöhnert, J.; Franz, K. J.; Nitz, M.; Imperiali, B.; Schwalbe, H. J. Am. Chem. Soc. 2003, 125, 13338-13339.
Table 1. Amino Acid Sequences of Lanthanide Binding Peptides ${ }^{a}$

\begin{tabular}{|c|c|}
\hline & $0 \quad 1223445678991011121314151617$ \\
\hline $\mathrm{LBT}^{\mathrm{b}}$ & Y I DTNNDGW Y E G D E L L A \\
\hline LBT2 & YVDTNNDGA Y E G D E L \\
\hline LBT3 & YVDTNNDGA Y E G D E L C \\
\hline LBT4 & Y VDTNNDGA Y E G D E \\
\hline LBT5 & YCDTNNDGA Y E G D E L \\
\hline
\end{tabular}

${ }^{a}$ Cysteine residues are highlighted in black. Residues in contact with the metal ion are shown with a gray background. ${ }^{b}$ LBT1 is one of the peptides optimized for lanthanide binding and luminescence by Imperiali and co-workers..$^{39}{ }^{c}$ D-Amino acid.

Most of these tags are not available commercially and/or suffer from mobility of the tag relative to the protein. The mobility poses a particularly serious problem, as the magnitudes of the $\Delta \chi$ and alignment tensors are reduced by averaging,, 33 whereas paramagnetic relaxation enhancement (PRE) remains highly effective irrespective of the mobility of the tag. Except for the protein fusions, all tags are tethered to the protein via disulfide bonds which tend to be flexible. The design of fusion proteins without a flexible linker between the protein and the lanthanide binding peptide is equally difficult. ${ }^{36}$ Tag mobility is reduced for tags that are anchored to the protein via two disulfide bonds, ${ }^{29,32,33}$ but this requires two appropriately spaced Cys residues in the protein and only one of the published doubleanchor tags ${ }^{32}$ avoids the peak doubling arising from diastereomers that form when metal coordination is possible with different chiralities. $5,26,29,38$

Among the lanthanide binding tags, peptide tags stand out for their commercial accessibility, chiral purity, and rigidity of attachment owing to their bulkiness. ${ }^{37}$ LBTs can be attached to any single Cys residue on the protein surface, so that Cys residues engineered at different sites of the protein can provide access to different $\Delta \chi$ tensor orientations. As mutant proteins are time-consuming to prepare and mutations have the potential to affect the protein structure in unforeseen ways, it would be more attractive to achieve the desired variation in the $\Delta \chi$ tensor orientation by different tags attached to the same Cys residue. Here we show that different tensor orientations for PCS and RDC measurements can readily be obtained by site-specific lanthanide labeling of the protein using LBT variants with Cys residues in different positions (Table 1). Large PCS and RDC values were obtained even with lanthanides of intermediate paramagnetic strength. Furthermore, knowledge of the $\Delta \chi$ tensor orientation in LBT adds control over the tensor orientation with respect to the protein.

\section{Experimental Section}

Sample Preparation. A uniformly ${ }^{15} \mathrm{~N}$-labeled sample of the N-terminal DNA-binding domain of the E. coli arginine repressor (residues 1-78, $\operatorname{ArgN}$ ) was expressed and purified as described. ${ }^{40}$ Peptides were synthesized chemically by using the 9-fluorenylmethyloxycarbonyl (FMOC) method on a Rainin Symphony/Multiplex peptide

(36) Martin, L. J.; Hähnke, M. J.; Nitz, M.; Wöhnert, J.; Silvaggi, N. R.; Allen, K. N.; Schwalbe, H.; Imperiali, B. J. Am. Chem. Soc. 2007, 129, 71067113.

(37) Su, X.-C.; Huber, T.; Dixon, N. E.; Otting, G. ChemBioChem 2006, 7, 1599-1604.

(38) Pintacuda, G.; Moshref, A.; Leonchiks, A.; Sharipo, A.; Otting, G. J. Biomol NMR 2004, 29, 351-361.

(39) Nitz, M.; Franz, K. J.; Maglathlin, R. L.; Imperiali, B. ChemBioChem 2003, 4, 272-276.

(40) Sunnerhagen, M.; Nilges, M.; Otting, G.; Carey, J. Nat. Struct. Biol. 1997, 4, 819-826. 
synthesizer. The peptides were ligated to Cys68 of ArgN by forming a disulfide bridge and loaded with lanthanides $\left(\mathrm{Ln}^{3+}\right)$ by titration with a $20 \mathrm{mM}$ solution of $\mathrm{Ln}^{3+}$ as described. ${ }^{37}$ The final NMR samples contained about $50 \mu \mathrm{M}$ protein in a buffer of $20 \mathrm{mM}$ MES ( $\mathrm{pH} 6.5$ ) and $4 \mathrm{mM}$ glycine. The apo-forms of the ArgN-LBT constructs were reconstituted by dialysis with DTPA. All NMR samples of LBTs without ArgN contained in addition 4 mM DTT. Samples of free LBTs and diamagnetic complexes of LBTs with equimolar concentrations of $\mathrm{Lu}^{3+}$ contained $2 \mathrm{mM} \mathrm{LBT}$ at $\mathrm{pH}$ 6.5. Complexes between LBT4 and mixtures of lanthanides contained $1.5 \mathrm{mM} \mathrm{LBT4}, 0.7 \mathrm{mM} \mathrm{LuCl}_{3}$, and $0.9 \mathrm{mM} \mathrm{YbCl} 3, \mathrm{TmCl}_{3}$, or $\mathrm{Er}(\mathrm{OAc})_{3}$ (final concentrations) at $\mathrm{pH} 6.5$.

NMR Spectroscopy. All NMR measurements were performed on a Bruker AV $800 \mathrm{MHz}$ NMR spectrometer equipped with a TCI cryoprobe. NMR spectra of LBTs were recorded at 10 and $25^{\circ} \mathrm{C} .{ }^{1} \mathrm{H}$ NMR resonance assignments of $\mathrm{Lu}^{3+}$ complexes of LBT2, LBT3, and LBT4 were obtained by 2D NOESY and TOCSY spectra, using mixing times of 120 and $60 \mathrm{~ms}$, respectively. EXSY spectra were recorded using a NOESY pulse sequence with water presaturation and a jumpreturn sequence ${ }^{41}$ to replace the $90^{\circ}\left({ }^{1} \mathrm{H}\right)$ pulse following the mixing time. The EXSY experiments used mixing times of 5 and $10 \mathrm{~ms}$ at 25 and $10{ }^{\circ} \mathrm{C}$, respectively. NMR spectra of ArgN-LBT constructs were recorded at $10{ }^{\circ} \mathrm{C}$. Residual dipolar couplings ${ }^{1} D_{\mathrm{HN}}$ were measured as the ${ }^{15} \mathrm{~N}$-doublet splitting of the diamagnetic sample minus that of the paramagnetic sample using the IPAP pulse sequence. ${ }^{42}$

Data Evaluation. PCS were measured as the difference of the chemical shifts observed in the presence of a paramagnetic $\mathrm{Ln}^{3+}$ ion minus the chemical shifts of the corresponding $\mathrm{Lu}^{3+}$ complex. Corrections for residual anisotropic chemical shifts are unimportant for $\mathrm{Tm}^{3+}, \mathrm{Er}^{3+}$, and $\mathrm{Yb}^{3+}{ }^{43}$ and were omitted. An in-house program was used to fit metal ion positions and $\Delta \chi$ tensors simultaneously by minimizing the mean square deviations between observed PCS and PCS that were back-calculated using eq 1 . Conformer 8 of the family of NMR conformers of ArgN (PDB accession code $1 \mathrm{AOY}^{40}$ ) fits the experimental RDCs best and was used as the reference structure for all tensor fits. Conformer 1 of the crystal structure of the LBT1- $\mathrm{Tb}^{3+}$ complex (PDB accession code $1 \mathrm{TJB}^{45}$ ) was used for fitting the $\Delta \chi$ tensors in the LBT4- $\mathrm{Ln}^{3+}$ complexes, centering the $\Delta \chi$ tensor at the crystallographically determined metal position. Only PCS of backbone amide protons were used in the fit to avoid complications from potentially heterogeneous side chain conformations. In addition, only paramagnetic shifts from spins removed by at least seven chemical bonds from the lanthanide ion were considered in the fits in order to minimize possible contributions from contact shifts. ${ }^{46}$

Alignment tensors were determined using the program Pales, assuming an order parameter $S=1 .{ }^{44}$ Mean values and standard deviations of the generalized angles ${ }^{11}$ between alignment tensors were calculated by a Monte Carlo approach. For each ArgN-LBT construct, 100 replicate data sets were generated by addition of normal distributed error $(\sigma=1 \mathrm{~Hz})$ to the experimental RDC values and 100 alignment tensors were fitted, resulting for each of the six ArgN-LBT pairs in a total of 10000 alignment tensor comparisons from which the average and standard deviation of the generalized angle were computed. In the case of $\mathrm{ArgN}-\mathrm{LBT} 3$, the variation of RDC values combined with similar magnitudes of the $A_{z z}$ and $A_{y y}$ eigenvectors resulted in $\sim 20 \%$ of the fits in a nearly equivalent alignment tensor where the $A_{z z}$ and $A_{y y}$ eigenvectors had interchanged. Since generalized angles are not invariant to such a swap of axes, these solutions were ignored.

Figures 1 and 4 were prepared with Molmol. ${ }^{47}$

(41) Plateau, P.; Guéron, M. J. Am. Chem. Soc. 1982, 104, 7310-7311.

(42) Ottiger, M; Delaglio, F.; Bax, A. J. Magn Reson. 1998, 131, 373-378.

(43) John, M.; Park, A. Y.; Pintacuda, G.; Dixon, N. E.; Otting, G. J. Am. Chem. Soc. 2005, 127, 17190-17191.

(44) Zweckstetter, M.; Bax, A. J. Am. Chem. Soc. 2000, 122, 3791-3792.

(45) Nitz, M.; Sherawat, M.; Franz, K. J.; Peisach, E.; Allen, K. N.; Imperiali, B. Angew. Chem., Int. Ed. 2004, 43, 3682-3685.

(46) Peters, J. A.; Nieuwenhuizen, M. S. J. Magn. Reson. 1985, 65, 417-428.

(47) Koradi, R.; Billeter, M.; Wüthrich, K. J. Mol. Graph. 1996, 14, 51-55.

\section{Results}

$\Delta \chi$-Tensor Determination of $\mathbf{Y b}^{3+}, \mathrm{Tm}^{3+}$, and $\mathrm{Er}^{3+}$ in LBT4. NOESY spectra of the $\mathrm{Lu}^{3+}$ complexes of LBT2, LBT3, LBT4, and LBPT5 showed that the metal-binding motif observed in the crystal structure of the LBT1- $\mathrm{Tb}^{3+}$ complex ${ }^{45}$ is structurally conserved in solution. Similar chemical shifts of the $\mathrm{Lu}^{3+}$ complexes further confirmed their structural conservation. ${ }^{1} \mathrm{H}$ chemical shifts of $\mathrm{Yb}^{3+}$ and $\mathrm{Tm}^{3+}$ complexes ranged over 83 and $117 \mathrm{ppm}$, respectively, whereas the effective spectral width for $\mathrm{Er}^{3+}$ complexes was less because the more pronounced paramagnetic relaxation enhancement associated with this lanthanide ${ }^{48}$ broadened the most strongly shifted peaks beyond detection (Figure S1). Resonance assignments of paramagnetic complexes of LBT4 were obtained by homonuclear 2D EXSY spectra using approximately equimolar ratios of paramagnetic lanthanide ions and diamagnetic $\mathrm{Lu}^{3+}$. Even at low temperature $\left(10^{\circ} \mathrm{C}\right)$, diamagnetic and paramagnetic lanthanides exchanged rapidly, allowing the transfer of the resonance assignments from the diamagnetic to the paramagnetic state in experiments of very short mixing times. ${ }^{23,25,49}$ The assignment of the amide proton resonances in the paramagnetic complexes was further verified by comparing EXSY spectra recorded in $90 \% \mathrm{H}_{2} \mathrm{O} / 10 \% \mathrm{D}_{2} \mathrm{O}$ and $100 \% \mathrm{D}_{2} \mathrm{O}$.

Using the crystal structure of the $\mathrm{LBT} 1-\mathrm{Tb}^{3+}$ complex as a model ${ }^{45}$ we determined the $\Delta \chi$ tensors of $\mathrm{Yb}^{3+}, \mathrm{Tm}^{3+}$, and $\mathrm{Er}^{3+}$ in LBT4 (Table 2). The long axes of the tensors were found to be similarly, but not identically, oriented for all three metal ions (Figure 1). Greater uncertainties are associated with the tensors of $\mathrm{Tm}^{3+}$ and $\mathrm{Er}^{3+}$ than with the tensor of $\mathrm{Yb}^{3+}$ due to smaller numbers of PCS measured (Table S2).

PCS Observed in ArgN Tagged with Different LBTs. Following the attachment of an LBT to Cys68 of ${ }^{15} \mathrm{~N}$-labeled ArgN, a diamagnetic complex was formed with $\mathrm{Lu}^{3+}$. 3D NOESY- ${ }^{15} \mathrm{~N}-\mathrm{HSQC}$ spectra confirmed that the 3D structure of the protein was maintained with $\mathrm{Lu}^{3+}$ complexes of LBT2 to LBT5.

${ }^{15} \mathrm{~N}-\mathrm{HSQC}$ spectra of ArgN-LBT complexes with the paramagnetic ions $\mathrm{Er}^{3+}, \mathrm{Tm}^{3+}$, or $\mathrm{Yb}^{3+}$ showed displacements of the cross-peaks along nearly parallel lines, which was used to assign the cross-peaks in the paramagnetic states. The maximal RDC measured for backbone amides of the ArgNLBT2 complexes with $\mathrm{Er}^{3+}, \mathrm{Tm}^{3+}$, and $\mathrm{Yb}^{3+}$ was 12.0, 22.6, and $7.4 \mathrm{~Hz}$, respectively, at $10{ }^{\circ} \mathrm{C}$. Owing to the larger magnetic moment, $\mathrm{Er}^{3+}$ causes more pronounced PRE than $\mathrm{Tm}^{3+}$, resulting in fewer and broader cross-peaks. ${ }^{48}$ In contrast, the paramagnetic line-broadening induced by $\mathrm{Yb}^{3+}$ was sufficiently small to allow the measurement of PCS of Cys68 and neighboring residues, but no PCS value greater than $0.7 \mathrm{ppm}$ was observed. We subsequently measured PCS and RDC data of backbone amides for the $\mathrm{Tm}^{3+}$ complexes of all ArgN-LBT constructs.

Figure 2 shows that $\mathrm{Tm}^{3+}$ generated significant PCS throughout the ArgN molecule for the derivatives with LBT2 to LBT5. In view of the result that Tyr1 and Leu16 of the LBT- $\mathrm{Ln}^{3+}$ complexes are located in regions of opposite sign of the PCS (Figure 1), one would expect that attachment to a protein via

(48) Bleaney, B. J. Magn. Reson. 1972, 8, 91-100.

(49) John, M.; Headlam, M.; Dixon, N. E.; Otting, G. J. Biomol. NMR 2007 $37,43-51$

(50) Golding, R. M.; Halton, M. P. Aust. J. Chem. 1972, 25, 2577-2581. 
Table 2. $\Delta \chi$-Tensor Parameters of LBT4 Complexes with $\mathrm{Yb}^{3+}, \mathrm{Tm}^{3+}$, and $\mathrm{Er}^{3+}$ a

\begin{tabular}{|c|c|c|c|c|c|c|c|c|c|c|}
\hline temperature & $\mathrm{Ln}^{3+}$ & $\Delta \chi_{\mathrm{ax}}$ & $\Delta \chi_{\mathrm{rh}}$ & $\Delta \chi_{x x}$ & $\Delta \chi_{y y}$ & $\Delta \chi_{z z}$ & tensor axis & \multicolumn{3}{|c|}{ coordinates of tensor axes } \\
\hline $25^{\circ} \mathrm{C}$ & $\mathrm{Er}^{3+}$ & 8.1 & 4.3 & -0.6 & -4.8 & 5.4 & $\begin{array}{l}x \\
y \\
z\end{array}$ & $\begin{array}{r}0.665 \\
-0.507 \\
0.548\end{array}$ & $\begin{array}{l}0.555 \\
0.827 \\
0.091\end{array}$ & $\begin{array}{r}-0.499 \\
0.244 \\
0.832\end{array}$ \\
\hline $25^{\circ} \mathrm{C}$ & $\mathrm{Tm}^{3+}$ & 25.3 & 4.9 & -6.0 & -10.9 & 16.9 & $\begin{array}{l}x \\
y \\
z\end{array}$ & $\begin{array}{r}0.699 \\
-0.509 \\
0.501 \\
\end{array}$ & $\begin{array}{l}0.517 \\
0.845 \\
0.137\end{array}$ & $\begin{array}{r}-0.493 \\
0.163 \\
0.854 \\
\end{array}$ \\
\hline $25^{\circ} \mathrm{C}$ & $\mathrm{Yb}^{3+}$ & 5.9 & 2.2 & -0.9 & -3.1 & 4.0 & $\begin{array}{l}x \\
y \\
z\end{array}$ & $\begin{array}{r}0.092 \\
-0.656 \\
0.749 \\
\end{array}$ & $\begin{array}{l}0.796 \\
0.501 \\
0.341\end{array}$ & $\begin{array}{r}-0.599 \\
0.564 \\
0.568\end{array}$ \\
\hline $10^{\circ} \mathrm{C}$ & $\mathrm{Er}^{3+b}$ & & & & & & & & & \\
\hline $10^{\circ} \mathrm{C}$ & $\mathrm{Tm}^{3+}$ & 30.1 & 4.2 & -7.9 & -12.1 & 20.1 & $\begin{array}{l}x \\
y \\
z\end{array}$ & $\begin{array}{r}0.714 \\
-0.478 \\
0.512 \\
\end{array}$ & $\begin{array}{l}0.478 \\
0.866 \\
0.143 \\
\end{array}$ & $\begin{array}{r}-0.512 \\
0.143 \\
0.847 \\
\end{array}$ \\
\hline $10^{\circ} \mathrm{C}$ & $\mathrm{Yb}^{3+}$ & 8.1 & 1.4 & -2.0 & -3.4 & 5.4 & $\begin{array}{l}x \\
y \\
z\end{array}$ & $\begin{array}{r}0.260 \\
-0.634 \\
0.728\end{array}$ & $\begin{array}{l}0.779 \\
0.583 \\
0.231\end{array}$ & $\begin{array}{r}-0.571 \\
0.507 \\
0.646\end{array}$ \\
\hline
\end{tabular}

${ }^{a}$ The tensor parameters are in units of $10^{-32} \mathrm{~m}^{3}$. The tensor axes refer to conformer 1 of the crystal structure (PDB code $1 \mathrm{TJB}^{45}$ ). ${ }^{b}$ The ${ }^{1} \mathrm{H}$ NMR signals of the LBT4- $\mathrm{Er}^{3+}$ complex were too broad at $10^{\circ} \mathrm{C}$ to assign a sufficient number of cross-peaks that can be assumed to be unaffected by contact shifts. $\left(\mathrm{Er}^{3+}\right.$ causes larger contact shifts than $\mathrm{Tm}^{3+}$ or $\left.\mathrm{Yb}^{3+} .{ }^{50}\right)$

a

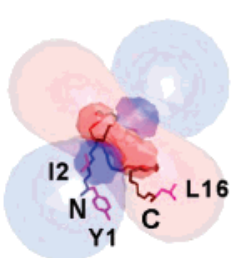

b

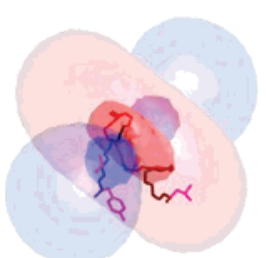

C

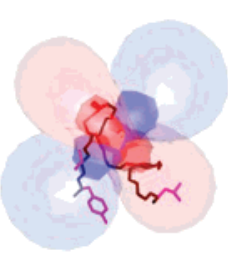

Figure 1. PCS isosurfaces of LBT4 complexed with (a) $\mathrm{Yb}^{3+}\left(10^{\circ} \mathrm{C}\right)$, (b) $\mathrm{Tm}^{3+}\left(10{ }^{\circ} \mathrm{C}\right)$, and (c) $\mathrm{Er}^{3+}\left(25^{\circ} \mathrm{C}\right)$ at $\mathrm{pH}$ 6.5. The isosurfaces represent PCS of \pm 10 and $\pm 0.5 \mathrm{ppm}$ for the $\mathrm{Er}^{3+}$ and $\mathrm{Yb}^{3+}$ complexes and \pm 20 and $\pm 1 \mathrm{ppm}$ for the $\mathrm{Tm}^{3+}$ complex. Blue: positive PCS. Red: negative PCS.

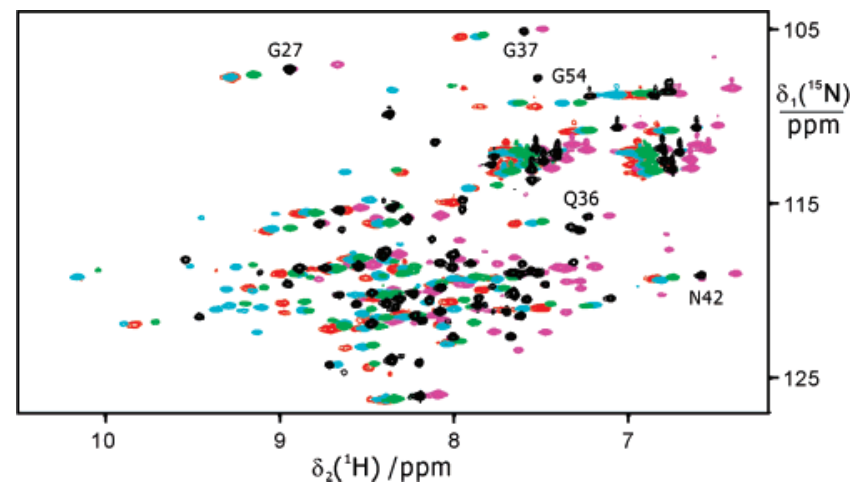

Figure 2. Superposition of ${ }^{15} \mathrm{~N}-\mathrm{HSQC}$ spectra of uniformly ${ }^{15} \mathrm{~N}$-labeled ArgN derivatized at Cys68 with $\mathrm{Tm}^{3+}$ complexes of LBT2 (cyan), LBT3 (magenta), LBT4 (green), and LBT5 (red). The superposition also displays the spectrum of the $\mathrm{ArgN}-\mathrm{LBT} 5-\mathrm{Lu}^{3+}$ complex (black) with the assignment of some of the resolved cross-peaks. The spectra were recorded at $10{ }^{\circ} \mathrm{C}$ and $\mathrm{pH} 6.5$.

the $\mathrm{N}$ - or C-terminal ends of the LBT should endow the protein with PCS of opposite sign. This is indeed the case, as demonstrated by the ${ }^{15} \mathrm{~N}-\mathrm{HSQC}$ cross-peaks of the paramagnetic $\mathrm{ArgN}-\mathrm{LBT} 2-\mathrm{Tm}^{3+}$ and $\mathrm{ArgN}-\mathrm{LBT} 3-\mathrm{Tm}^{3+}$ complexes which are generally displaced in opposite directions relative to those of the diamagnetic $\mathrm{ArgN}-\mathrm{LBT} 2-\mathrm{Lu}^{3+}$ complex (Figure 2). As expected for exposure of the protein to different aspects of the tag's $\Delta \chi$ tensor, the PCS were largely but not completely

anticorrelated (Figure 3a). Therefore, LBT2 and LBT3 present a suitable pair to resolve ambiguities arising from multiple solutions of eq 1.

RDCs Observed in ArgN Tagged with Different LBTs. RDCs of the ArgN-LBT constructs were measured by comparison of the one-bond ${ }^{1} \mathrm{H}-{ }^{15} \mathrm{~N}$ splittings observed with $\mathrm{Tm}^{3+}$ and $\mathrm{Lu}^{3+}$. RDCs of up to $22 \mathrm{~Hz}$ were measured in an $18.8 \mathrm{~T}$ magnet ( $800 \mathrm{MHz}$ ). Only the ArgN-LBT3 complex showed somewhat reduced RDC magnitudes (Table S4), indicating greater mobility of the peptide with respect to the protein. The axial and rhombic components of the alignment tensors determined from the backbone ${ }^{15} \mathrm{~N}-{ }^{1} \mathrm{H}$ RDCs (Table 3) reflected the shape of the $\Delta \chi$ tensor determined for free LBT4 (Table 2). As expected, their orientations differed between different ArgN-LBT constructs (Figure 4a). The generalized angle between the alignment matrices ${ }^{11}$ was close to orthogonal between ArgN-LBT3 and the other ArgN-LBT constructs and $\sim 14^{\circ}$ between all other pairs (Table 4 ). These differences were sufficient to yield significantly different RDCs (Table S4).

Structure of the ArgN-LBT Complexes from $\Delta \chi$ and Alignment Tensors. Owing to the distance of the lanthanide from the protein (greater than about $10 \AA$ ) combined with the limited size of ArgN, each LBT exposed almost all of the amide protons of ArgN to PCS of the same sign (Figure 2, Table S4). As a result, the $\Delta \chi$-tensor parameters and metal positions relative to the $\operatorname{ArgN}$ molecule could not be fitted as accurately as the alignment tensors which are independent of the metal position and for which both positive and negative RDC values could be measured. The fitting of the PCS by a single $\Delta \chi$ tensor is further obstructed by any motions of the peptide tag relative to the protein. Nonetheless, the $\Delta \chi$ tensors determined from the PCS were similarly oriented as the alignment tensors (Figure S2) and the $\mathrm{Tm}^{3+}$ positions found by the fitting algorithm were within a plausible distance (10.6 to $14.9 \AA$ ) of the sulfur of Cys68 of ArgN (Figure 4a).

We subsequently built structural models of the ArgN-LBT complexes by simple superpositions of the $\Delta \chi$ tensor determined for the LBT4- $\mathrm{Tm}^{3+}$ complex at $10{ }^{\circ} \mathrm{C}$ with the alignment tensors observed for $\operatorname{ArgN}$ centered at the metal positions 
a

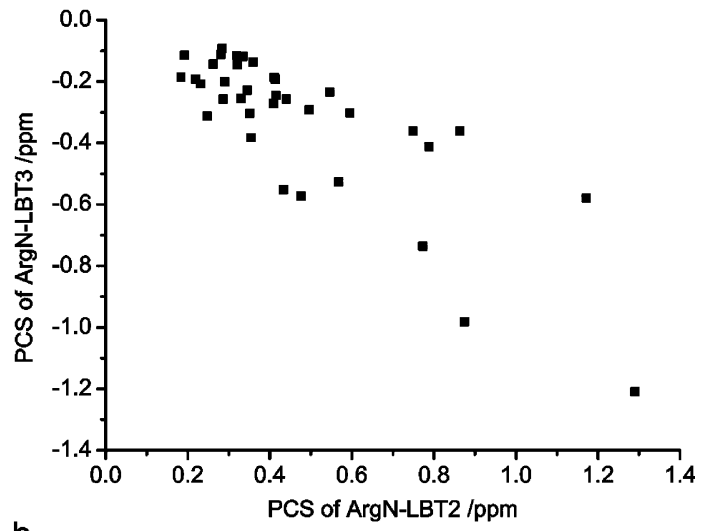

b

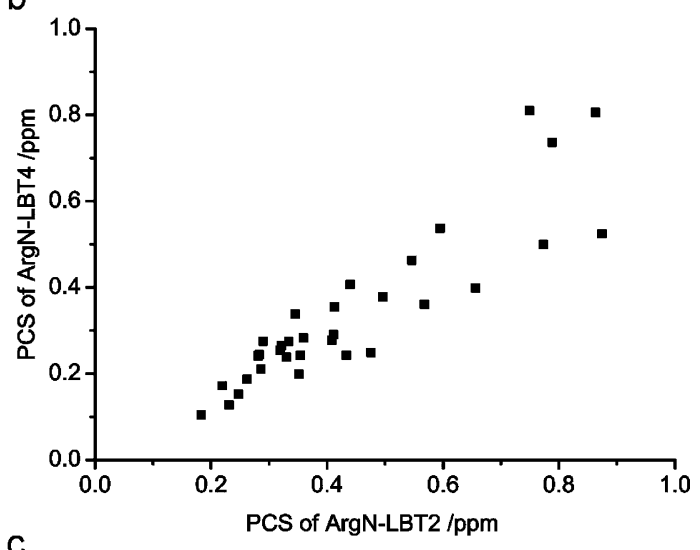

C

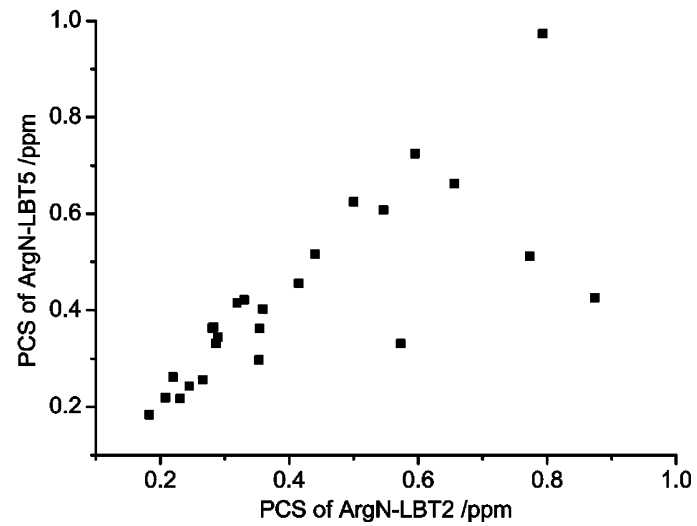

Figure 3. Correlations of the PCS measured for backbone amide protons of ArgN derivatized with different LBTs. The plots correlate amide-proton PCS of the $\mathrm{Tm}^{3+}$ complexes of (a) ArgN-LBT3 versus ArgN-LBT2, (b) ArgN-LBT4 versus ArgN-LBT2, and (c) ArgN-LBT5 versus ArgNLBT2.

determined from the $\Delta \chi$-tensor fits of ArgN. Using the crystal coordinates of $\mathrm{LBT}^{45}$ to represent the LBTs, the tensor superpositions yielded a unique orientation for each LBT which fulfilled the criteria that (i) the presumable position of the Cys residue in the LBT must be within appropriate distance of the Cys68 thiol group and (ii) no steric clashes must be present that could not be relieved by minor adjustments of side chain conformations (Figure 4b). Considering the simplicity of the approach, the distance of $1.8 \AA$ Aetween Cys68 $\mathrm{S}^{\gamma}$ and the Cys 16 side chain of LBT3 (approximated by the $\mathrm{C}^{\gamma}$ atom of Leu16 in the LBT1 structure ${ }^{45}$ ) is remarkably close to the length of a $\mathrm{S}-\mathrm{S}$ bond. Also the Cys2 side chain of LBT5 (approximated by the $\mathrm{C}^{\gamma 1}$ atom of Ile2 in LBT1) is within $4.7 \AA$ of Cys $68 \mathrm{~S}^{\gamma}$. Finally, the gap of $6.4 \AA$ between Cys $68 \mathrm{~S}^{\gamma}$ and the $\mathrm{C}^{\alpha}$ atoms of Tyr 1 in LBT2 could readily be bridged by the additional $\mathrm{N}$-terminal Cys residue.

\section{Discussion}

Paramagnetic LBTs provide exceptionally flexible tools for inducing different alignment tensors, offering many distinctive advantages over conventional alignment media, fusion proteins, and chemical lanthanide tags. (i) LBTs are commercially available in chirally pure form; (ii) protein-LBT constructs achieve molecular alignments in the absence of alignment media, keeping the chemical environment the same for aligned and unaligned samples, avoiding the possibility of chemical incompatibilities with the alignment media, and facilitating the recovery of the protein; (iii) LBTs can be attached with high yield to any free cysteine residue using well-established thiol chemistry ${ }^{37}$ (iv) the relatively large distance between the lanthanide and the target protein minimizes PRE of the protein spins; (v) unlike fusion proteins, LBTs are not isotope labeled together with the target protein, avoiding the introduction of additional cross-peaks in the diamagnetic reference state; (vi) LBTs allow modification of the $\Delta \chi$ and alignment tensors by using different lanthanide ions, ${ }^{37}$ by attachment to cysteine residues engineered at different surface locations of the protein or, more importantly, by different attachment modes to a single cysteine as shown in the present work; (vii) knowledge of the $\Delta \chi$ tensor with respect to free LBT allows strategic positioning of the $\Delta \chi$ tensor with respect to the protein by choosing an LBT $-\mathrm{Ln}^{3+}$ complex with a suitably positioned cysteine residue; (viii) LBTs are less prone to motional averaging than most other lanthanide-binding tags, resulting in large PCS and RDC effects with lanthanide ions associated with only moderate PRE.

The short tether presented by a disulfide bond limits the mobility of LBTs due to steric interactions between the rather bulky $\mathrm{LBT}-\mathrm{Ln}^{3+}$ complex and the protein. This advantage is easily lost in fusion proteins, if LBTs are attached to already flexible $\mathrm{N}$ - or C-terminal polypeptide segments. ${ }^{34-36}$ The similarity of the alignment tensors observed for the ArgN constructs with LBT2, LBT4, and LBT5 (Figure 4) demonstrates that steric interactions are more important determinants of the tensor orientation than linker conformations.

In principle, knowledge of the $\Delta \chi$ tensor of an $\mathrm{LBT}-\mathrm{Ln}^{3+}$ complex provides prior knowledge of the axial and rhombic components of the $\Delta \chi$ and alignment tensors measured for the protein in a protein-LBT- $\mathrm{Ln}^{3+}$ complex. Proportionality between alignment and $\Delta \chi$ tensors can, however, strictly be expected only for rigid molecules ${ }^{9}$ and any motion of the LBT moiety relative to the protein results in average tensors. Notably, however, the averaging over different alignment tensors results in a new effective alignment tensor, whereas the average of different $\Delta \chi$ tensors with different metal positions can only approximately be represented by an effective $\Delta \chi$ tensor because PCS depend on the distance of the lanthanide ion from the nuclear spins (eq 1). As a consequence, the parameters of a single effective $\Delta \chi$ tensor determined by fitting experimental with back-calculated PCS can particularly be influenced by data from protein spins located near the LBT.

In the case of the ArgN-LBT- $\mathrm{Tm}^{3+}$ complexes, the orientations of the $\Delta \chi$ and alignment tensors derived from the backbone amide groups of $\mathrm{ArgN}$ were similar but not identical (Tables 3 and S5 and Figures 4 and S2). The differences may in part be 
Table 3. Alignment Tensor Parameters Determined from RDCs of ArgN Backbone Amide Protons in Complexes with LBT2 to LBT5 and $\mathrm{Tm}^{3+} \mathrm{a}$

\begin{tabular}{|c|c|c|c|c|c|c|c|c|c|}
\hline construct & $10^{4} A_{\mathrm{ax}}$ & $10^{4} A_{\text {th }}$ & $\Delta \chi_{x x}$ & $\Delta \chi_{y y}$ & $\Delta \chi_{z z}$ & tensor axis & \multicolumn{3}{|c|}{ coordinates of tensor axes } \\
\hline $\operatorname{ArgN}-\mathrm{LBT} 2$ & 10.4 & 3.0 & -4.1 & -10.3 & 14.4 & $\begin{array}{l}x \\
y \\
z\end{array}$ & $\begin{array}{r}-0.816 \\
0.071 \\
0.573\end{array}$ & $\begin{array}{l}0.470 \\
0.658 \\
0.588\end{array}$ & $\begin{array}{r}-0.335 \\
0.750 \\
-0.570\end{array}$ \\
\hline $\mathrm{ArgN}-\mathrm{LBT} 3$ & 5.0 & 3.2 & -0.1 & -6.8 & 6.9 & $\begin{array}{l}x \\
y \\
z\end{array}$ & $\begin{array}{r}-0.506 \\
0.810 \\
0.296\end{array}$ & $\begin{array}{r}0.689 \\
0.585 \\
-0.427\end{array}$ & $\begin{array}{l}-0.519 \\
-0.012 \\
-0.855\end{array}$ \\
\hline $\operatorname{ArgN}-\mathrm{LBT} 4$ & 8.4 & 1.6 & -4.2 & -7.4 & 11.6 & $\begin{array}{l}x \\
y \\
z\end{array}$ & $\begin{array}{r}-0.885 \\
-0.154 \\
0.439\end{array}$ & $\begin{array}{l}0.199 \\
0.728 \\
0.656\end{array}$ & $\begin{array}{r}-0.421 \\
0.668 \\
-0.613\end{array}$ \\
\hline $\operatorname{ArgN}-\mathrm{LBT} 5$ & 9.2 & 0.8 & -5.5 & -7.2 & 12.7 & $\begin{array}{l}x \\
y \\
z\end{array}$ & $\begin{array}{r}-0.767 \\
-0.034 \\
0.640\end{array}$ & $\begin{array}{l}0.422 \\
0.725 \\
0.544\end{array}$ & $\begin{array}{r}-0.483 \\
0.688 \\
-0.542\end{array}$ \\
\hline
\end{tabular}

${ }^{a}$ The tensor axes refer to conformer 8 of the $\operatorname{ArgN}$ solution structure (PDB code $1 \mathrm{AOY}$ ). Equivalent $\Delta \chi$ tensor parameters (in units of $10^{-32} \mathrm{~m}^{3}$ ) are shown for comparison with the data of Table 2. $A_{\mathrm{ax}}$ and $A_{\mathrm{rh}}$ values were translated into equivalent $\Delta \chi_{\mathrm{ax}}$ and $\Delta \chi_{\mathrm{rh}}$ values using eq 3 , and the $\Delta \chi_{\mathrm{xx}}, \Delta \chi_{\mathrm{yy}}$, and $\Delta \chi_{\mathrm{zz}}$ components were calculated using $\Delta \chi_{\mathrm{ax}}=\Delta \chi_{\mathrm{zz}}-\left(\Delta \chi_{\mathrm{xx}}+\Delta \chi_{\mathrm{xx}}\right) / 2, \Delta \chi_{\mathrm{rh}}=\Delta \chi_{\mathrm{xx}}-\Delta \chi_{\mathrm{yy}}$, and $\Delta \chi_{\mathrm{xx}}+\Delta \chi_{\mathrm{yy}}+\Delta \chi_{\mathrm{zz}}=0$.

a

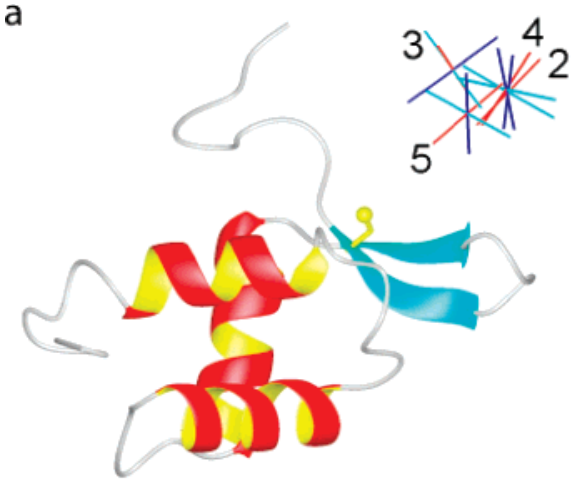

b

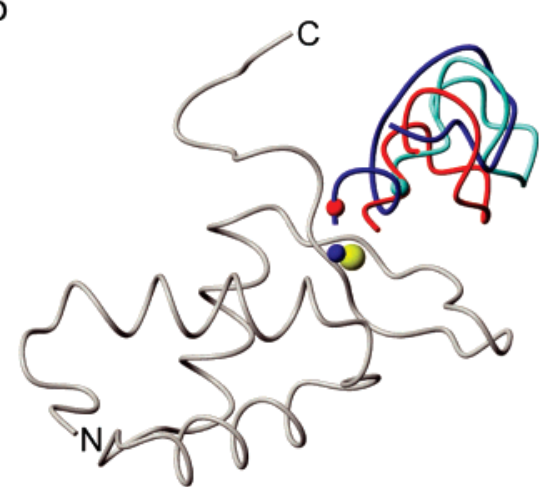

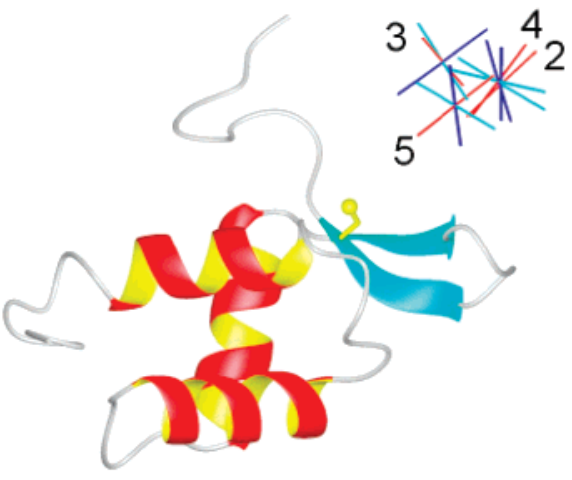

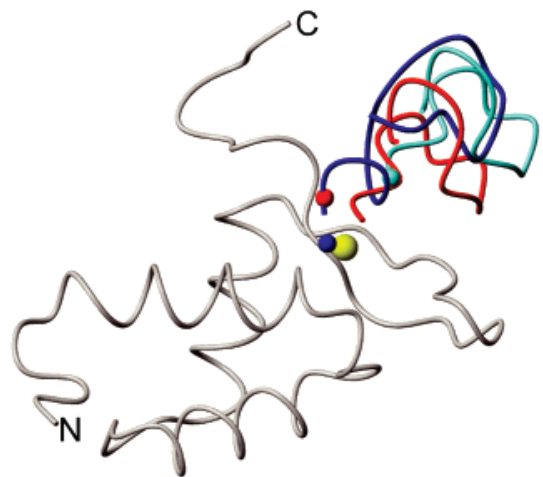

Figure 4. Alignment tensors and structures of $\mathrm{ArgN}-\mathrm{LBT}-\mathrm{Tm}^{3+}$ complexes. (a) Stereoview of a ribbon representation of ArgN illustrating the alignment tensor axes resulting from magnetic alignment by different $\mathrm{LBT}-\mathrm{Tm}^{3+}$ complexes. The tensor axes are centered at the positions of the metal ions as determined by a $\Delta \chi$-tensor fit of the PCS, showing the $x$-, $y$-, and $z$-axes in cyan, blue, and red, respectively. The numbers refer to the LBT numbering in Table 1. The side chain of Cys68 is highlighted in yellow, with the sulfur atom shown as a yellow sphere. (b) Stereoview of the ArgN backbone with the

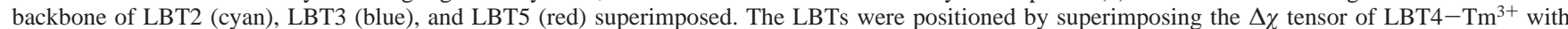
the alignment tensors shown in (a). All LBTs are represented by the crystal structure of LBT1. ${ }^{45}$ The following atoms are highlighted as spheres to identify reference points for the attachments of LBT2, LBT3, and LBT5 to Cys68 $\mathrm{S}^{\gamma}$ (yellow sphere) of ArgN: Tyr1 $\mathrm{C}^{\alpha}$ (cyan), Leu16 $\mathrm{C}^{\gamma}$ (blue), Ile2 $\mathrm{C}^{\gamma 1}$ (red). LBT4 is located and oriented very similarly as LBT2 (not shown).

attributed to the lesser accuracy of the $\Delta \chi$-tensor determination that resulted in a much greater variation of the rhombic components (Table S5) than for the alignment tensors (Table $3)$. In the case of the $\operatorname{ArgN}-\mathrm{LBT} 3-\mathrm{Tm}^{3+}$ complex, the $\Delta \chi$ tensor fit even led to a swap of the $y$ and $z$ tensor axes (Table S5 and Figure S2). This is probably a consequence of the increased mobility of LBT3 with respect to the $\mathrm{ArgN}$ molecule which is evidenced by a reduced magnitude of the $A_{\mathrm{ax}}$ and $A_{\mathrm{rh}}$ values of this complex compared with the other LBT constructs
Table 4. Mean Generalized Angles between the Alignment Tensors of ArgN Generated by $\mathrm{Tm}^{3+}$ Complexes of LBT2-5a

\begin{tabular}{cccc}
\hline & ArgN-LBT3 & ArgN-LBT4 & ArgN-LBT5 \\
\hline ArgN-LBT2 & $60 \pm 1$ & $13 \pm 4$ & $14 \pm 4$ \\
ArgN-LBT3 & & $71 \pm 2$ & $68 \pm 2$ \\
ArgN-LBT4 & & & $16 \pm 4$ \\
\hline
\end{tabular}

$a$ Values given in degrees. Error estimates were obtained from 100 replicate RDC data sets with random normal variations of $1 \mathrm{~Hz}$ (see Experimental Section). 
(Table 3). Clearly, mobility also affects the accuracy of the ArgN-LBT structures (Figure 4b), although only largeamplitude motions could probably conceal the predominant conformation.

It may ultimately prove difficult to prevent all averaging effects, as even a recently published chemical tag that was attached to the protein via two disulfide bridges showed differences between the alignment and $\Delta \chi$ tensors. ${ }^{33}$ Nonetheless, it will be possible to use the $\Delta \chi$-tensor parameters determined with the assumption of a rigid system for studies of intermolecular interactions by measurement of PCS induced in the binding partner, ${ }^{6,21}$ provided that the interaction site is far from the LBT attachment site and the tensor parameters are determined from PCS of nuclear spins that are located not too close to the LBT. Similar to the ArgN-LBT models built in the present study, increased accuracy in the structure determination of intermolecular complexes can be expected if, in addition, RDC data are available to determine the alignment tensor associated with the $\Delta \chi$ tensor. When using LBTs to obtain different molecular alignments, it may be worthwhile to exploit the different extent of motional averaging associated with different tethers to achieve different effective alignment tensors. Finally, since paramagnetically induced molecular alignment is, to first order, independent of molecular weight (eq 3), lanthanide labeling presents a particularly attractive tool for measurements of RDCs in large molecules. The new capability of exposing proteins to differently oriented $\Delta \chi$ tensors greatly enhances the information content of these experiments.

Acknowledgment. We thank Dr. Guido Pintacuda for Mathematica routines for $\Delta \chi$-tensor determination from PCS and Christophe Schmitz for a program computing isosurface representations. Financial support from the Australian Research Council for a Federation Fellowship for G.O., the project, and towards the $800 \mathrm{MHz}$ NMR spectrometer at ANU is gratefully acknowledged.

Supporting Information Available: ${ }^{1} \mathrm{H}$ NMR resonance assignments of the LBT4- $\mathrm{Lu}^{3+}$ complex; EXSY spectra of LBT4 with $\mathrm{Lu}^{3+} / \mathrm{Yb}^{3+}, \mathrm{Lu}^{3+} / \mathrm{Tm}^{3+}$, and $\mathrm{Lu}^{3+} / \mathrm{Er}^{3+}$ mixtures; ${ }^{1} \mathrm{H}$ NMR resonance assignments of amide protons of LBT4 in complex with $\mathrm{Yb}^{3+}, \mathrm{Tm}^{3+}$, and $\mathrm{Er}^{3+}$; PCS and RDCs measured for ArgN-LBT complexes with $\mathrm{Tm}^{3+} ; \Delta \chi$ tensors of LBT2 to LBT5 as determined from PCS measured for ArgN. This material is available free of charge via the Internet at http://pubs.acs.org.

JA076564L 